\title{
Energy Saving in Electro-Hydraulic System Using Impedance Sensing
}

\author{
Kittiphong Poomphochana \\ Rajamangala University of Technology \\ Rattanakosin, \\ Thailand \\ kittiphong.p@rmutr.ac.th,
}

\author{
Pornjit Pratumsuwan and Watcharin Po-ngaen \\ King Mongkut’s University of Technology \\ North Bangkok \\ Thailand \\ vpn@kmutnb.ac.th
}

\begin{abstract}
In last decade, energy efficiency of hydraulic actuators systems has been especially important in industrial machinery applications. Even small improvements of efficiency in high loads fluid power system therefore often have a significant economic impact on the total cost. Fundamentally, most of these losses relates to motion control based on hydraulic resistance, this paper concerns the introduction of a new type of impedance controlled saving energy in hydraulic machinery. An impedance sensing concept is employed to optimize the quantitative energy of fluid power pressure and flow in hydraulic system. Results of experiment study are presented showing the potential improvement in term of energy saving and pressure servo performance offered by this method.
\end{abstract}

Keywords-Energy Saving; Electro-Hydraulic System; Impedance Sensing

\section{INTRODUCTION}

Energy efficiency of heavy machineries has become one of the most important topics in because of increased fuel costs, which is needed to save the environment. To meet the increased requirements on higher efficiency and better functionality, components and systems have been developed over the years. Fluid power transmission system has been used for a long time in all sorts of machinery and systems have many advantages over other technologies. The dynamic performance is superior when compared to electrical or electrical-mechanical drive systems in large power drive systems [1]. High performance of hydraulic systems still remains a priority, but systems during working period machine that use cylinder and hydraulic motor as an actuator may have several hydraulically functions, with three or more operating simultaneously, e.g. feeding, clamping bending, grinding, cutting, drilling and pressing are providing power for load, hydraulic power varies depending on load and during increase or decrease speed of cylinder or hydraulic motor. When the actuator is accelerated or decelerated using flow control valves there are much pressure drop in component is converted into heat energy which can have determinately effects on and the surrounding environment and energy loss in the system more than $45 \%$ change to heat generated in the system [2]. These results in an increasing of temperature, contamination, vibration, leakage and noise in hydraulic system these are all problems of the hydraulic machines. In recent decades, high performance of hydraulic systems still remains a priority, but systems which are energy efficient have been the focus of much study; The demands for highly efficient hydraulic drives has also increased. If the efficiency of hydraulic drive systems cannot be improved, many traditional applications in which they are found will be converted to other power drive systems. Therefore it is very challenging to find out how to reduce the energy loss and heat generation in a conventional hydraulic system and what is the key for energy saving if a common pump is used to supply flow rate to the circuit, this is primarily due to using a controller for electro-hydraulic system is developed to improve the energy saving performance of the hydraulic system considerations.

A conventional hydraulic system which is driven by a hydraulic pump operating at a constant speed of $1450 \mathrm{rpm}$ is typically used. During idle periods the motor continues to rotate at full speed, perhaps consuming $30-45 \%$ of full load amperage [3]. The hydraulic power which is function of flow and pressure varies as the actuator speed rises and falls at acceleration and deceleration period in response to cycle time of machines by controlling the rotating speed of the hydraulic pump and prevent unnecessary loss of motive energy by stopping the pump during idle time. A conventional hydraulic system which controlled by hydraulic or electric system, most of the electro-hydraulic system has low efficiency with high energy loss [4-7]. Therefore, this research is interested in a development of a power unit electrohydraulic energy saving system using a typical induction motor with an inverter controller. The inverter is characterized by load sensing by using impedance controller and employing a fixed displacement pump. To better understand the shortcomings regarding energy efficiency in any hydraulic system, it is important to look not only at the system itself, but also under what loading conditions it operates. In order to validate the ideas and theories presented in this research, the next section will give a background to some of the important of math modeling of hydraulic system.

\section{POWER UNIT IN HYDRAULIC SYSTEM}

In this section, hydraulic power unit system will be introduced. The following simple equation was used to describe a behavior of the hydraulic system. The output flow of hydraulic oil can be expressed as:

$$
Q_{p}=\frac{\omega \cdot V_{t h}}{2 \pi} \cdot \eta_{v o l}
$$

where $Q_{p}$ is the pump output flow in $\mathrm{m}^{3} / \mathrm{s}, \omega$ is the rotation angular speed, $V_{t h}$ is the theoretical volumetric displacement 
of the pump in $\mathrm{m}^{3} / \mathrm{rev}$, and $\eta_{\text {vol }}$ is its volumetric efficiency. The differential equation for the pump shaft is

$$
J_{p} \frac{d}{d t} \omega+T_{f, p}(\omega)=T_{\text {motor }}-\eta_{v o l} T_{p, t h}
$$

where the total equivalent inertia of the pump is $J_{p}, d \omega / d t$ is the pump angular acceleration, $T_{\text {motor }}$ is the drive torque, $T_{p, t h}$ is the theoretical torque required for compressing fluid, $T_{f, p}$ is the frictional torque, and the volumetric efficiency of the pump is $\eta_{\mathrm{vol}}$ The theoretical torque to compress the fluid can be modeled as follows

$$
T_{p, t h}=V_{t h}\left(p_{s}-p_{r t n}\right)
$$

where the theoretical volumetric displacement for the pump is $V_{t h}, p_{s}$ is the system pressure, and $p_{m}$ is the tank pressure in $\mathrm{Pa}$. The frictional torque can be modeled as follows

$$
T_{f, p}(\omega)=T_{v} \omega+\operatorname{sign}(\omega) \cdot\left[T_{c o}+T_{s o} \cdot e^{\left(\frac{-|\omega|}{C_{s}}\right)}\right]
$$

where $T_{v}$ is the viscous friction, $T_{c o}$ is the Coulomb friction, $T_{s o}$ is the static friction, and $C_{s}$ is the Stribeck friction. For an induction motor, rotor speed, frequency of the voltage source, number of poles and slip are interrelated according to the following equation:

$$
n=\frac{120 f_{1}}{P} \cdot(1-s)
$$

where $n$ is mechanical speed (rpm), $f_{l}$ is fundamental frequency of the input voltage $(\mathrm{Hz}), P$ is number of poles, and $s$ is slip factor in induction motor. The utilization of static frequency inverters comprehends currently the most efficient method to control the speed of induction motors. Inverters transform a constant frequency and constant amplitude voltage into a variable frequency and variable amplitude voltage. The variation of the power frequency supplied to the motor leads to the variation of the rotating field speed, which modifies the mechanical speed of the machine. The torque developed by the induction motor follows the equation below

$$
T=k_{1} \cdot \varphi_{m} \cdot I_{2}
$$

Despising the voltage drop caused by the stator impedance, the magnetizing flux is found to be

$$
\varphi_{m}=k_{2} \cdot \frac{V_{1}}{f_{1}}
$$

Where $T$ is torque available on the shaft (N.m), $\phi_{m}$ is magnetizing flux (Wb), $I_{2}$ is rotor current (A) depends on load, $V_{1}$ is stator voltage $(\mathrm{V})$, and $k_{1} \& k_{2}$ are constants depend on material and on the machine design. For the electro-hydraulic system is designed to mimic the function of a compression machine. Figure 1 illustrates the energy saving test rig in hydraulic system using in this research. The gear pump is coupling by induction motors and rotation angular speed is controlled by power electronically inverter. The pressure sensors are mounted strategically on the double acting cylinder to feedback to control system. The computer acts as a control unit in order to obtain the load energy for processing and then transmitting out control signals via DAQ card. For the output signal, digital signal is used to control valve 4/3 (closed-center position) for move in and out of the cylinder and analog control signal is used to adjust oil flow by varying the speed of the electric.

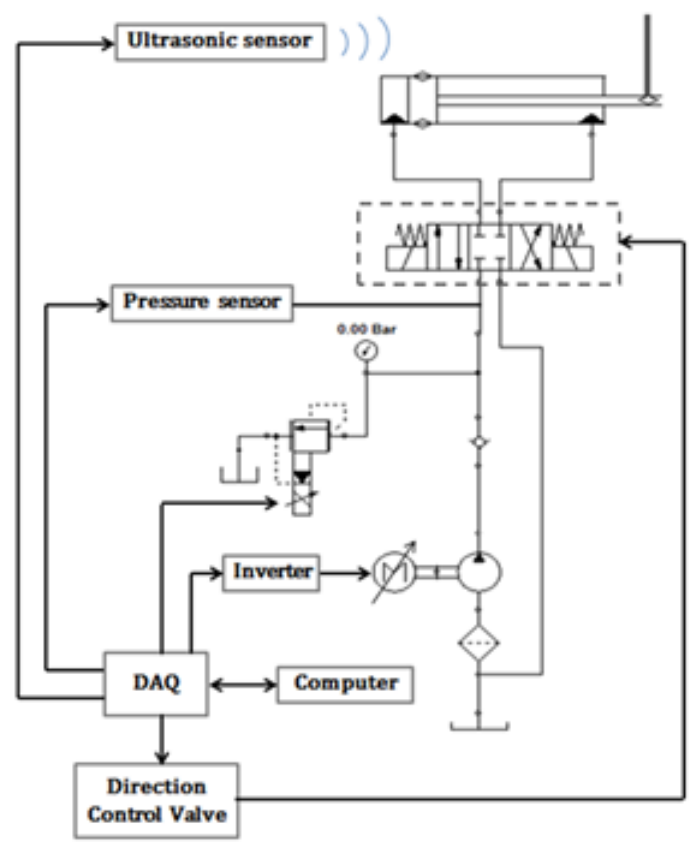

Figure 1 . The energy saving test rig in a impedance control hydraulic system

The impedance control objective is to control neither force (pressure) nor flow but their dynamic relation, the desired impedance, along each direction on the load space [8-10]. Impedance controllers possess some inherent robustness to environment modeling errors [11-14].The control objective of an impedance controller is to impose, along each direction of the load motion, a desired dynamic relation between the position of hydraulic cylinder and the pressure of working load. Usually, the desired impedance is chosen linear and of second order, as in a mass-springdamper system that may be expressed by this equation.

$$
F=M\left(\ddot{x}_{d}-\ddot{x}\right)+B\left(\dot{x}_{d}-\dot{x}\right)+K\left(x_{d}-x\right)
$$

where $\boldsymbol{M}, \boldsymbol{B}$ and $\boldsymbol{K}$ are constant, positive definite representing the desired inertia, damping, and stiffness system. Vectors $\mathbf{x}$ represent the actual and the desired, and $F$ 
represents the generalized load of hydraulic system exerts upon the cylinder. The impedance sensing function in hydraulic system using in this study may be expressed as

$$
F=7.05 \ddot{x}+4648424.24 \dot{x}+1813215.13 x
$$

\section{EXPERIMENT SETUP AND EXPERIMENTAL RESULTS}

Equipment used in this experiment is to mimic the function of the operation of the compression machine. The main equipment used in such experiments is shown in figure 2 and table 1 respectively.

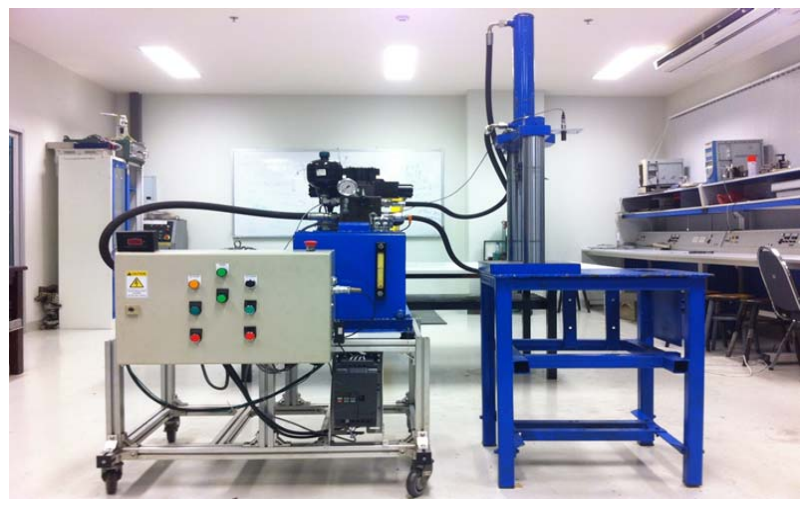

Figure 2. The test rig compression machine

TABLE 1. POWER CONSUMPTION OF ELECTRIC MOTOR

\begin{tabular}{|c|c|}
\hline Components & Descriptions \\
\hline Hydraulic pump & Gear pump, 14cc/rev \\
\hline Induction motor & 380V, 50Hz, 3.7kW \\
\hline Double acting cylinder & $\begin{array}{c}\text { Bore size 50mm, Stroke 500mm } \\
\text { Directional control valve }\end{array}$ \\
\hline Pressure relief vale & Control pressure 0-100bars \\
\hline Proportional pressure & $\begin{array}{c}\text { Voltage input 0-10volts, Control } \\
\text { pressure output }\end{array}$ \\
\hline relief valve & $\begin{array}{c}\text { Input pressure 0-100bars, Output } \\
\text { 0-10volts }\end{array}$ \\
\hline Pressure sensor & Inductive sensor (on/off) \\
\hline Proximity sensor & V/F 0-50Hz, 380V, 3.7kW \\
\hline Inverter & 0-20Amps \\
\hline Current sensor &
\end{tabular}

In design the electro-hydraulic system for use in experiments to simulate the operation of the compression machine, the sequence procedure is illustrated in the figure 3. The DAQ card cooperation with graphical programming is using to control and obtain the power consumption data from the experimental test rig. To evaluate any improvement in the hydraulic compression system, corresponding comparative control experiments were conducted by moving the cylinder press contract with the obstacle. The pressure of the operation was set at a 100 Bar.

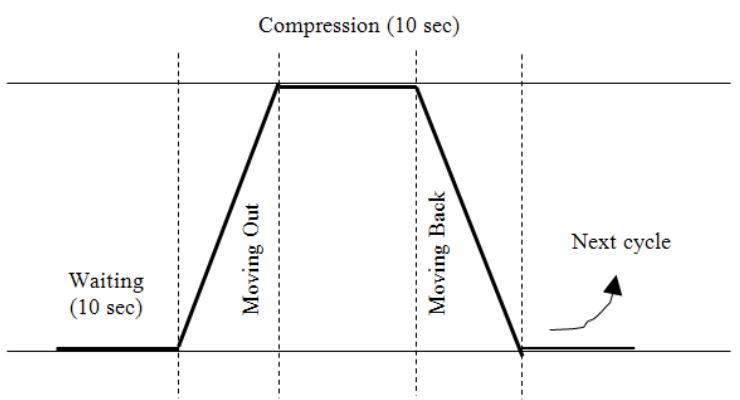

Figure 3. The cycle time of the compression machine

The dynamic response of pressure and current consummation was investigated. For the comparative pressure response results, figure 4 illustrates using a conventional, PID, and impedance controller. for the overall tracking of the pressure control could achieve satisfactory performance.

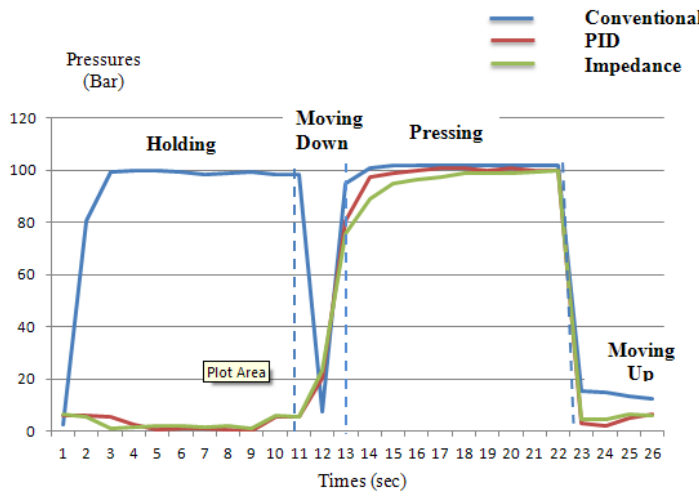

Figure 4. Pressure control dynamic response

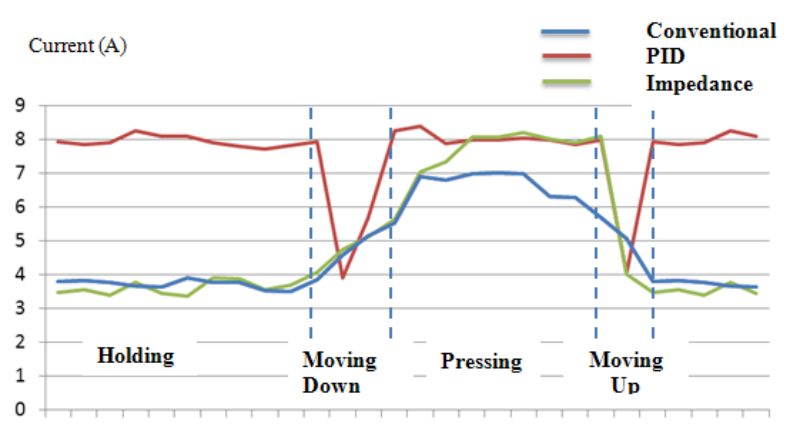

12345678910111213141516171819202122232425262728

Times (sec)

Figure 5. Comparison of power consumption

In order to compare the power consumption performance, when the machine operation using both conventional, PID and impedance control, the measured current from motor was used to evaluate the operation performance. Figure 5 is shown that the power consumption process. On waiting 
pressing, the conventional system consumption is about 8 amperes, for the control system with PID, and impedance controller's consumption are about 3.5-4 amperes. During press all technique consumes about 8.0 amperes approximately which showed in table 2.

TABLE 2 POWER CONSUMPTION OF ELECTRIC MOTOR

\begin{tabular}{|c|c|c|c|}
\hline $\begin{array}{c}\text { Control } \\
\text { Framewor } \\
\text { k }\end{array}$ & $\begin{array}{c}\text { Without } \\
\text { Feedback } \\
\text { control }\end{array}$ & PID & Impedance \\
\hline$\left(\mathbf{k W}^{*} \mathbf{h r}\right)$ & 3.79307 & 2.86219 & 2.81885 \\
\hline $\begin{array}{c}\text { Saving } \\
\text { Percentage }\end{array}$ & 0 & 24.54153 & 25.68411 \\
\hline
\end{tabular}

Table 2 shows that the inverter control with PID controller and impedance can reduce the power consumption of $24.54 \%$ and $25.68 \%$ of the conventional system.

\section{CONCLUSION}

As applications of electro-hydraulic system become increasingly widespread, the demand for low cost, highlevel control performance and significant energy saving schemes gets more significant. In this paper, impedance controller is developed to improve the energy saving and pressure servo performance of the electro-hydraulic system. The proposed control schemes were employ to control the inverter to adjust flow of hydraulic oil of by varying an electric motor with strategically coupling with hydraulic gear pump. The experimental results showed that using an impedance controller in electro-hydraulic system can reduce power consumption up to $25.68 \%$ compared to the conventional system. Furthermore, the robust performance of pressure servo can be archived from using this impedance controller.

\section{ACKNOWLEDGMENT}

The completion of this research had been done with full supports from Research and Development Institute, Rajamangala University of Technology Rattanakosin. The authors thank Center of Fluid Power Technology and Automatic Control, Faculty of Engineering,Rajamangala University of Technology Rattanakosin and Department of Teacher Training in Mechanical Engineering, Faculty of Technical Education, King Mongkut's University of Technology North Bangkok, which provided great help during this research.

\section{REFERENCES}

[1] Li,C.C., X.D. Lin, Zhou, X. Bao and J. Huang. Fuzzy control of electro-hydraulic servo systems based on automatic code generation. Proceeding of the 6th International Conference on Intelligent Systems Design and Applications, Oct.16-18, IEEE Computer Society, Washington DC, USA, 2006, pp. 244-247.

[2] Kwanchai Sinthipsomboon. Industrial Hydraulic, Se-education public company limited, 1987, pp. 25-87.

[3] Darrel Janesak and Dave Roepp. Hybrids make a move to the plant floor, Hydraulics \& pneumatics, August 2006, pp. 32-49.

[4] [Takayuki Imamura, Yuzo Sawada, Masashi Ichikawa, and Hirokazu Nakamura. Energy-Saving Hybrid Hydraulic System Comprising Highly Efficient IPM Motor and Inverter for Injection Molding and Manufacturing Machine, Japan, September 2008, pp. 117-120.

[5] [Radek manasek. Simulation of a electrohydraulic Load-sensing system with ac motor and Frequency change, Czech Republic, Hamburg 2000, pp. 311-324.

[6] [Guo Rui and Zhao Jingyi "Research of electro-hydraulic control system design and energy saving characteristic in the new drawbead test bed" International Conference on Fluid Power and Mechatronics ,17-20 Aug ,2011,pp 301-305

[7] Lovrec D.,Deticek E., Faber F., “Electro-Hydraulic Load Sensing with Close Control Actuator" Journal of Advance Production and Management ,Vol 4,pp 93-109

[8] [Hogan, N.: Impedance Control: an Approach to Manipulation: Part IIII. ASME Journal of

[9] Dynamic Systems, Measurement, and Control, Vol. 107 (1985) 1-24

[10] [Seraji, H., Colbaugh, R.: Force Tracking in Impedance Control. The International Journal of

[11] Robotics Research, Vol. 16, N. 1 (1997) 97-117

[12] Lu, Z., Goldenberg, A. A.: Robust Impedance Control and Force Regulation: Theory and

[13] Experiments. The International Journal of Robotics Research, Vol. 14, N. 3 (1995) 225-254

[14] Anderson, R. J., Spong, M. W.: Hybrid Impedance Control of Robotic Manipulators. IEEE

[15] Journal of Robotics and Automation, Vol. 4, N. 5 (1988) 549-555. 